\title{
Treatment of giant sialolithiasis on wharton's duct
}

\author{
Jae-Seek You ${ }^{1,2}$, Su-Gwan Kim ${ }^{1,2 *}$, Ji-Su Oh ${ }^{1,2}$, and Na-Ra Shin ${ }^{3}$ \\ ${ }^{1}$ Department of Oral and Maxillofacial Surgery, School of Dentistry, Chosun University, Gwangju 61452, Repulic of Korea \\ ${ }^{2}$ Oral Biology Research Institute, Chosun University, Gwongju 61452, Republic of Korea \\ ${ }^{3}$ Department of Oral and Maxillofacial Surgery, Chosun Universtiy Dental Hospital, Gwangju 61452, Repulic of Korea
}

(Received Feb. 9, 2017; Revised version received Feb. 26, 2017; Accepted Mar. 3, 2017)

\begin{abstract}
Sialolithiasis is one of the most common diseases occurring in salivary glands. Sialoliths are characterized by duct closure due to calculus deposits in the salivary gland and ducts, causing edema and pain. Sialolithiasis is most prevalent in the submandibular gland. Most of the sialoliths are small in size (less than $10 \mathrm{~mm}$ ), and giant sialoliths (greater than $15 \mathrm{~mm}$ ) are rarely reported. This case reports the successful removal of giant sialolithiasis of $45 \mathrm{~mm}$ or more, by an intraoral approach.
\end{abstract}

KEY WORDS: Sialolith, Giant sialolithiasis, Submandibular gland, Whartons duct

\section{Introduction}

Sialolithiasis is one of the most common diseases that occur in the salivary glands. It is mainly found in the major salivary glands and the most common occur region is the submandibular gland. It also exists in the parotid gland and sublingual gland $[1,2]$. Males are affected twice as much as females and a peak incidence is in middle age (30 60 years old) [3]. The reason for the most prevalent occurrence in the submandibular gland is the duct is long and had an adverse anatomical feature that cases the duct to turn rapidly. The submandibular gland has higher alkalinity, and viscosity of calcium and phosphate than other salivary glands [4]. The size of the sialoliths is reported to be mostly less than $10 \mathrm{~mm}$. Although not precisely defined, a type of sialolith with a size of $10 \mathrm{~mm}$ or more is referred to as an unusual size or a giant size sialolith [5]. Iqbal et al. [6] classified giant salivary gland sialoliths over $15 \mathrm{~mm}$ in size. This giant sialolith is rarely reported,

\section{*Corresponding author: Su-Gwan Kim}

Department of Oral and Maxillofacial Surgery, School of Dentistry, Chosun University, 309 Pilmun-daero, Dong-gu, Gwangju 61452, Repulic of Korea

Tel.: +82-62-220-3815, Fax: +82-62-228-7316

E-mail: sgckim@chosun.ac.kr and in cases of giant sialolithiasis, swelling of salivary gland and pain appear as symptoms. The sialolith removal or both salivary gland and sialolith removal is required with the symptoms. This case report represents a 60 -yearold woman who underwent the removal of giant sialolithiasis of $45 \mathrm{~mm}$ or more in the left submandibular salivary gland by an intraoral approach with successful outcome. This case also reported with a review of the literature.

\section{Case Report}

A 60-year-old female patient was admitted to Department of Oral and Maxillofacial Surgery with the chief complaint of periodic pain and edema in the left submandibular region. No specific findings were found in the underlying disease or systemic medical history. In clinical examination with palpation, pain and hardness were observed in the left submandibular region, and the same symptoms were observed in the floor of the mouth on the left side (Fig. 1). On panoramic radiographs, radiopaque calcifications were observed in the left mandibular body (Fig. 2). Computed tomography revealed radiopaque calcareous material along the left submandibular salivary gland (Fig. 3). On the basis of clinical and radiological findings, 


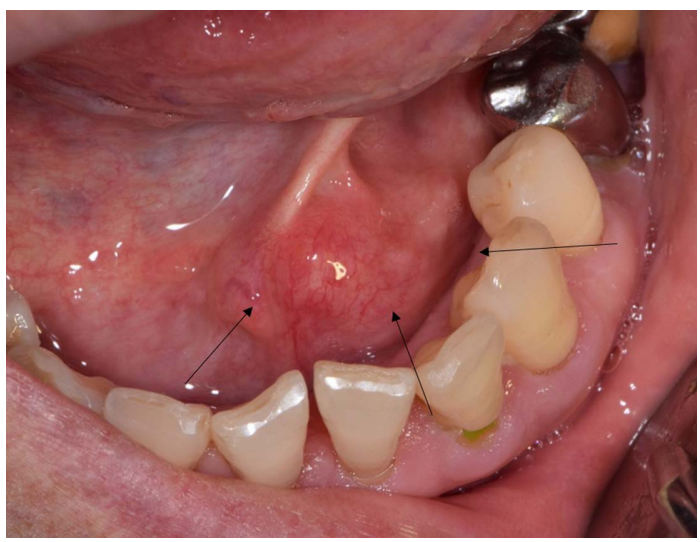

Fig. 1. Pre-operative intraoral view.

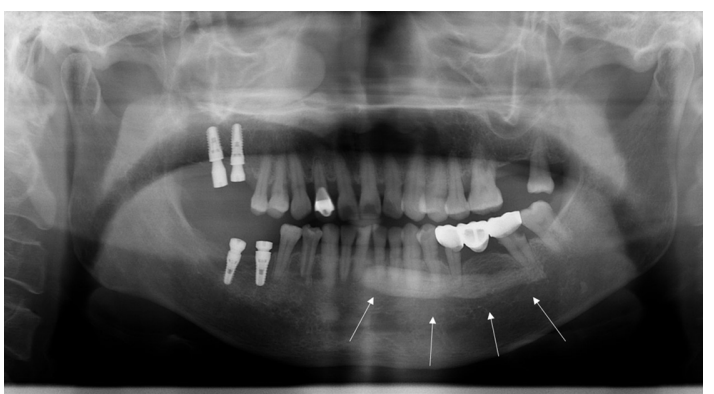

Fig. 2. Panoramic radiograph shows large radiopaque mass at the left mandibular area.

a giant sialolithiasis is diagnosed in the submandibular salivary gland. Under general anesthesia, the sialolith removal or submandibular gland extirpation with sialolith removal was planned. The tongue was pulled to the opposite side and the left submandibular region was pushed upward from the outside of the mouth to raise the floor of the mouth, and then the position of sialolith was palpated. Thereafter, the position of the sialolith was determined and a $1.5 \mathrm{~cm}$ of minimal incision was made in the floor of

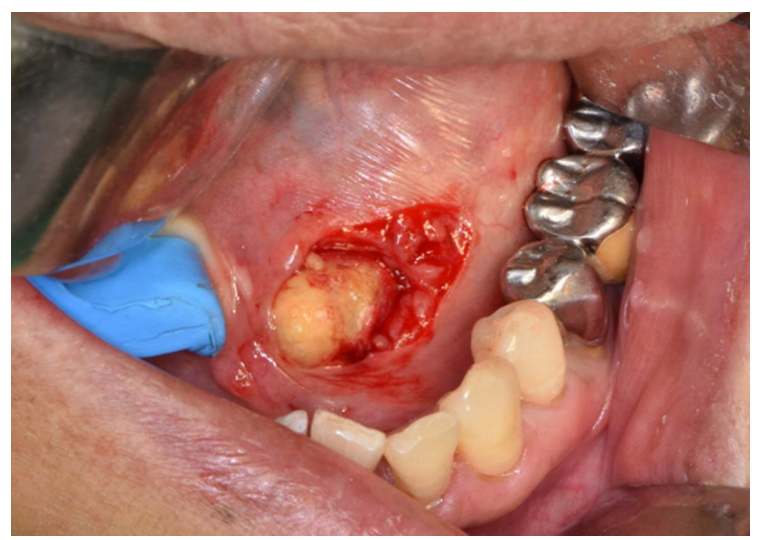

Fig. 4. Intraoral photograph while removing sialolith.

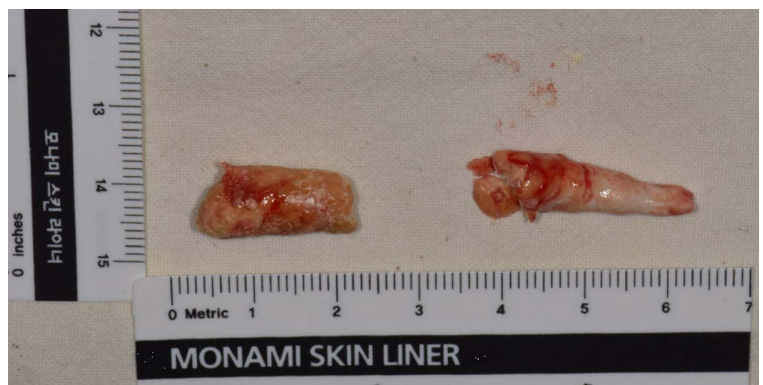

Fig. 5. The removal sialolith was measured $47 \mathrm{~mm} \times 12 \mathrm{~mm}$.

mouth and the sialolith was exposed through exfoliation (Fig. 4). The sialolith was divided into 2 3 parts, but salivary gland extirpation was not performed because normal salivary secretion was confirmed and the removal of all sialoliths was easy by an intraoral approach. A $47 \mathrm{~mm} \times$ $12 \mathrm{~mm}$ sized sialolith was removed (Fig. 5), and a cutdown tube was inserted to prevent stenosis of the salivary duct after the removal. The salivary duct and mucosal tissue were sutured with absorbable surgical sutures (Fig. 6), and histological examination of the extracted sialolith was
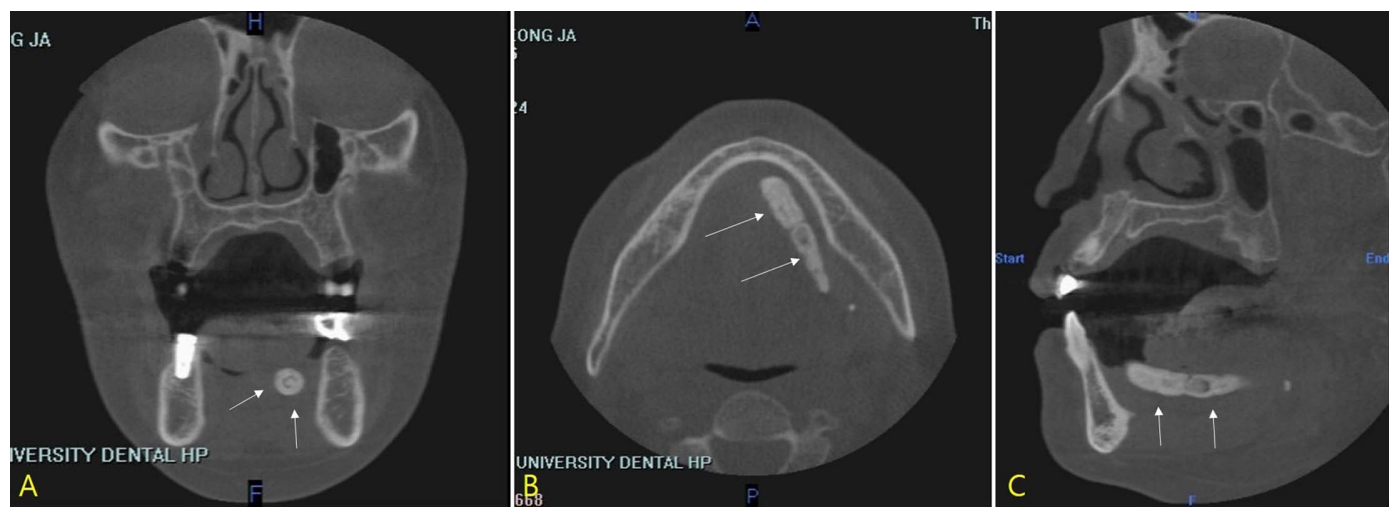

Fig. 3. Pre-operative CT view. (A. coronal view, B. axial view, C. sagittal view) 


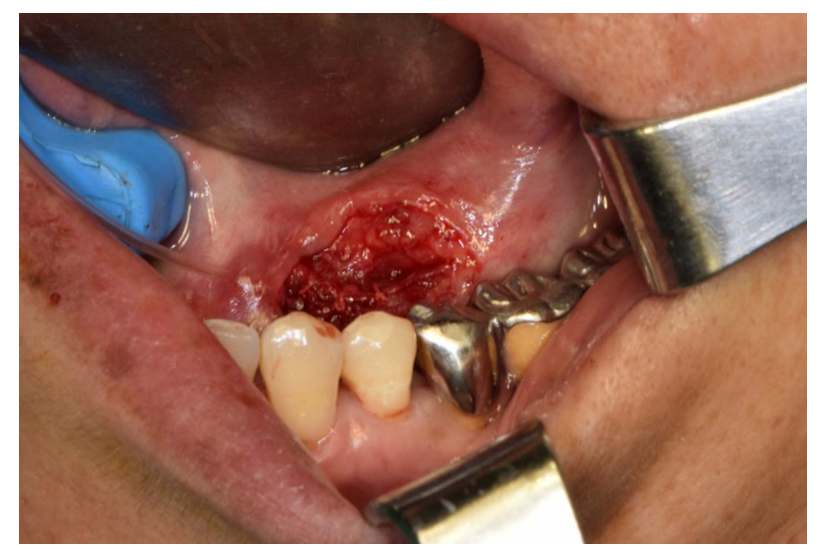

Fig. 6. The cut-down tube was inserted to exposed duct of submandibular gland for normal saliva secretion.

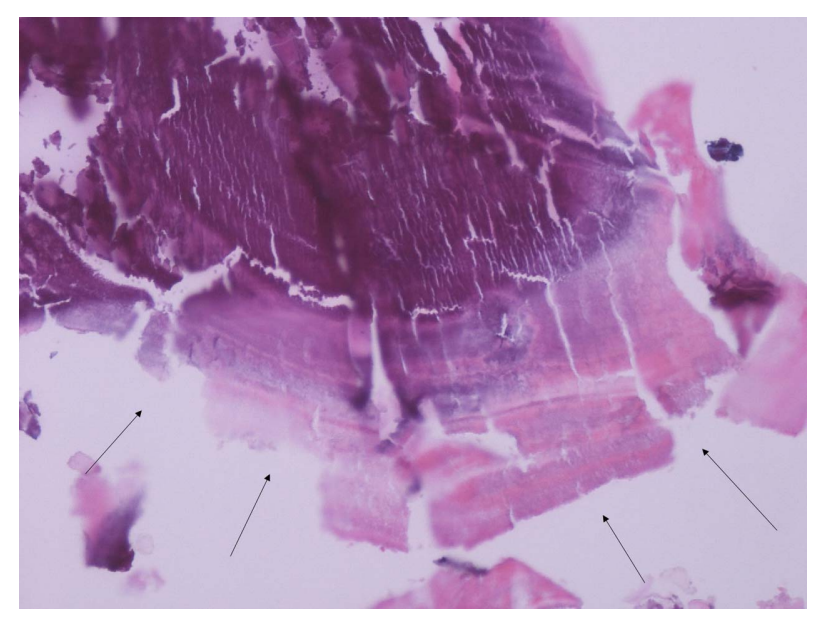

Fig. 7. Histologic findings. Round-shaped stony hard materials show lamellating apprearance of amorphous tissue. (H\&E staining, $\times 200$ )

performed (Fig. 7). Antibiotics and analgesic agents were prescribed for one week after the operation. After 2 weeks, the cut-down tube was removed and saliva was normally secreted (Fig. 8).

\section{Discussion}

Sialolith occurs in the submandibular and submandibular salivary ducts more than $80 \%, 5 \sim 20 \%$ in the parotid glands, and $1 \sim 2 \%$ in the sublingual and minor salivary glands $[2,6]$. The case of Giant sialolithiasis larger than $15 \mathrm{~mm}$ is rarely reported, but most of them were found in the submandibular gland and some were found in the parotid gland [7, 8]. A giant sialolithiasis was found in the submandibular duct in this case, $47 \mathrm{~mm}$ in length and $12 \mathrm{~mm}$ in width. The exact cause of the sialolith is unknown, but one supposition is the result of deposition of mineral salts around nidus bacteria, mucus or desquamated cells $[9,10]$. With this, the adverse anatomy of the submandibular gland mentioned above exerts influence on the development of giant sialolithiasis.

The treatment of these sialolithiasis is usually performed with conservative treatment using antibiotics and analgesic agents in the case of an inflammatory reaction, and surgical treatment is treated afterwards if acute inflammatory symptoms disappear. If the sialolith size is very small prior to surgical treatment, or if the sialolith is located at the orifice of the duct, the salivary secretion may be increase through ingestion of acidic food, or the sialolith may be discharged through the massage in the affected area $[11,12]$. However, if this treatment is not possible, a surgical treatment is needed. Various methods of surgical treatment are determined depending on the size and location of the sialolith. The sialolith, located in the opening or the distal part of the duct, can be easily removed by an intraoral approach. However, sialadenectomy may be performed simultaneously with the sialolith, located in the parenchyma of the salivary gland or in the proximal part of the duct. Most approaches to the submandibular gland
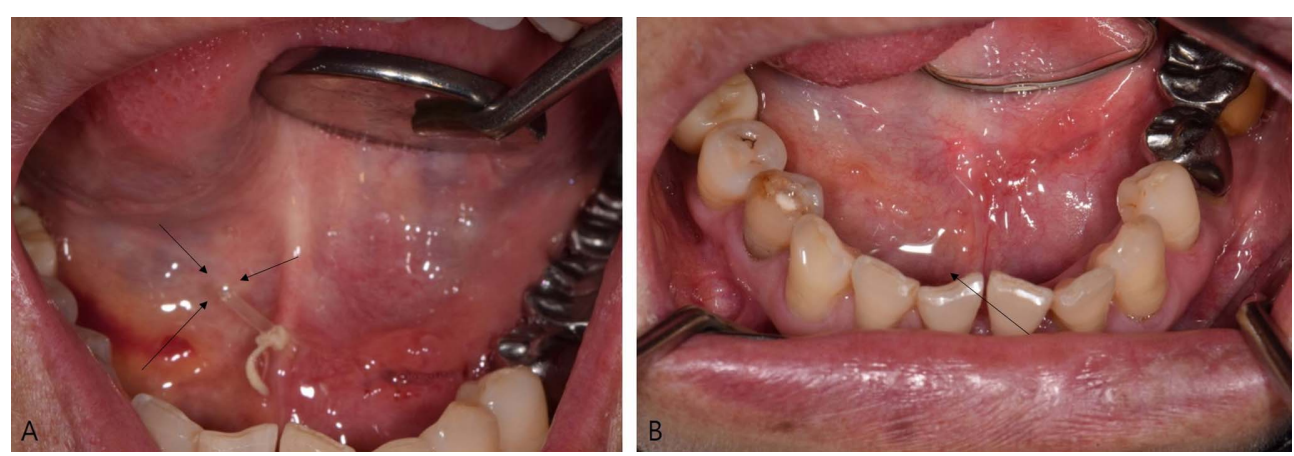

Fig. 8. Post-operative photograph. (A. 2weeks later, B. 3 weeks later) 
are accessed through a submandibular approach. This may lead to complications such as postoperative scarring and the possibility of the mandibular branch damage of the facial nerve. In consideration of the study shown that the function of salivary glands can be fully restored by simply removing the sialolith, it would be necessary to consider the removal of sialolith by an intraoral approach first if possible $[13,14]$. Recently, non-invasive treatments have been introduced, and an intraoral approach using sialendoscopy has been introduced. The success rate of the sialolith removal in the proximal part is low and the removal rate is significantly lower even if the size of the sialolith is small [15]. Another non-invasive method is sialolithotripsy. It is a non-invasive but expensive technique that requires special equipment to break down the sialolith with strong ultrasonic waves, and it is also reported that the success rate is significantly lower with the large sialolith [16]. Although a variety of non-invasive methods have been attempted, further studies are required. Efforts should be made to remove the sialolith without removing the salivary gland if the sialolith is in the parenchyma or in the proximal part of the duct. In this case, minimal incision was performed in comparison with the sialolith size, and the sialolith was removed by pushing it away from the proximal portion of the duct to the incision in the mouth.

An accurate diagnosis should be preceded in determining the surgical method of the sialolith. If a radiopaque image appears on a panoramic radiograph, a computed tomography scan is helpful to determine the exact location of the sialolith. If the sialolith is located and palpated on the mouth floor, it will be accessible to the mouth. In addition, if a CT confirms that the sialolith is located along the salivary gland duct as in this case, even large sialolith removal can be facilitated with minimal incision.

This case represents a polyethylene cut-down tube was inserted for maintaining the salivary duct after the sialolith removal to prevent stenosis of the duct and to maintain saliva drainage pathway. However, many satisfactory cases have been reported without inserting a catheter such as a cut-down tube after removing the sialolith by intraoral access $[12,17]$. Although the criteria for insertion of a catheter such as a cut-down tube has not been established, if symptoms such as abscesses, edema, and pain continue to recur or if stenosis of the duct is expected in the future, it would be better to insert the catheter to reduce additional procedures such as reoperation. In this case, a catheter, such as a cut-down tube, was inserted through the
Wharton's duct orifice for 2 weeks and the follow-up observation revealed that saliva was excreted normally through Wharton's duct orifice and complications like recurrence were not observed.

\section{Conclusions}

An accurate diagnosis is important through appropriate clinical and radiological examinations for the treatment of giant sialolithiasis. A precise assessment of the size or location of the sialolith may determine the non-invasive surgical procedure.

This case reported $47 \mathrm{~mm} \times 12 \mathrm{~mm}$ giant sialolith was removed noninvasively with minimal incision in the mouth, and successful results were obtained with a review of the literature.

\section{Acknowledgements}

This study was supported by research fund from Chosun University, 2014.

\section{Conflict of Interest}

The authors declare that they have no competing interests.

\section{ORCID}

Jae-Seek You 0000-0001-7638-9583

Su-Gwan Kim 0000-0002-0424-9984

Ji-Su Oh 0000-0002-8369-5025

Na-Ra Shin 0000-0002-8351-495X

\section{References}

1. Lustmann J, Regev E, Melamed Y. Sialolithiasis. A survey on 245 patients and a review of the literature. Int J Oral Maxillofac Surg 1990;19:135-138. doi: http://dx. doi.org/10.1016/S0901-5027(05)80127-4.

2. Bodner L. Giant salivary gland calculi: diagnostic imaging and surgical management. Oral Surg Oral Med Oral Pathol Oral Radiol Endod 2002;94:320-323. doi: http:// dx.doi.org/10.1067/moe.2002.123863. 
3. Marchal F, Dulguerov P. Sialolithiasis management: The state of the art. Arch Otolaryngol Head Neck Surg 2003;129:951-956.

4. Sutay S, Erdag TK, Ikiz AO, Guneri EA. Large submandibular gland calculus with perforation of the floor of the mouth. Otolaryngol Head Neck Surg 2003;128:587-588.

5. Ledesma-Montes C, Garcés-Ortíz M, Salcido-García JF, Hernández-Flores F, Hernández-Guerrero JC. Giant sialolith: case report and review of the literature. J Oral Maxillofac Surg 2007;65:128-130. doi: http://dx.doi.org/ 10.1016/j.joms.2005.10.053.

6. Iqbal A, Gupta AK, Natu SS, Gupta AK. Unusually large sialolith of Wharton's duct. Ann Maxillofac Surg 2012;2: 70-73. doi: 10.4103/2231-0746.95327.

7. Iqbal SM, Murthy JG, Sharma N. Giant parotid calculus - an unusual presentation. J Laryngol Otol 1992;106: 446-447.

8. Chung IK, Kim JR, Kim UK, Shin SH, Kim YD, Byun JH, Jang WS. A clinical study of submandibular gland excision. J Korean Assoc Oral Maxillofac Surg 2004;30: 545-550.

9. Kim EA, Kim HS, Kim HK, Jung SM. Recurrent Sialolithiasis on Remnant Wharton's Duct Following Submandibular Gland Resection. Korean J Otorhinolaryngol-Head Neck Surg 2004;47:1185-1187.

10. Arunkumar KV, Garg N, Kumar V. Oversized submandibular gland sialolith: a report of two cases. J Maxillo- fac Oral Surg 2015;14:116-119. doi: 10.1007/s12663012-0361-y.

11. Williams MF. Sialolithiasis. Otolaryngol Clin North Am 1999;32:819-834.

12. Choi WS, Yoon HJ, Lee SH. Giant sialolithiasis of the submandibular gland: a case report. J Korean Assoc Oral Maxillofac Surg 2010;36:141-144.

13. Eun YG, Chung DH, Kwon KH. Advantages of intraoral removal over submandibular gland resection for proximal submandibular stones: a prospective randomized study. Laryngoscope 2010;120:2189-2192. doi: 10.1002/ lary. 21120.

14. Koch M, Iro H, Künzel J, Psychogios G, Bozzato A, Zenk J. Diagnosis and gland-preserving minimally invasive therapy for Wharton's duct stenoses. Laryngoscope 2012;122:552-558. doi: 10.1002/lary.22452.

15. Park S, Choi JS, Lim JY, Kim YM. Management of sialolithiasis of submandibular gland: sialendoscopy-assisted intraoral stone removal. Korean J OtorhinolaryngolHead Neck Surg 2013;56:217-221.

16. Siddiqui SJ. Sialolithiasis: an unusually large submandibular salivary stone. Br Dent J 2002;193:89-91. doi: 10.1038/sj.bdj.4801491.

17. Combes J, Karavidas K, McGurk M. Intraoral removal of proximal submandibular stones-an alternative to sialadenectomy? Int J Oral Maxillofac Surg 2009;38:813816. doi: 10.1016/j.ijom.2009.02.026. 